\title{
DINÂMICAS PRÉ E PÓS-COLOSTRAL DO ERITROLEUCOGRAMA, DA PROTEÍNA PLASMÁTICA TOTAL E DO FIBRINOGÊNIO DE CORDEIROS
}

\section{PRE AND POST-COLOSTRAL DYNAMICS OF ERYTHRO-LEUKOGRAM, TOTAL PLASMA PROTEIN, AND FIBRINOGEN OF LAMBS}

\author{
Damaris Ferreira de Souza ${ }^{1 *}$ \\ Luciana Helena Kowalski ${ }^{1}$ \\ Carlos Henrique Kulik ${ }^{1}$ \\ Ivan Roque de Barros Filho ${ }^{1}$ \\ Rosangela Locatelli Dittrich ${ }^{1}$ \\ Alda Lúcia Gomes Monteiro ${ }^{1}$ \\ ${ }^{1}$ Universidade Federal do Paraná, Curitiba, PR, Brasil. \\ *Autora para correspondência - fs.damaris@gmail.com
}

\section{Resumo}

O objetivo deste estudo foi caracterizar a dinâmica de alguns parâmetros hematológicos em cordeiros recém-nascidos sadios, antes e após a ingestão de colostro. Foram coletadas amostras sanguíneas de 28 cordeiros recém-nascidos, determinando-se o eritroleucograma, as concentrações de proteína plasmática total (PPT) e de fibrinogênio nos momentos pré e pós-colostro. Os dados foram analisados comparando-se a variabilidade dos parâmetros entre os dois momentos. $\mathrm{O}$ hematócrito $(\mathrm{P}<0,001)$, a concentração de hemoglobina $(\mathrm{P}<0,05)$ e o volume globular médio $(\mathrm{VGM})(\mathrm{P}<0,05)$ diminuíram após a ingestão de colostro, enquanto a concentração de hemoglobina globular média (CHGM) aumentou $(\mathrm{P}<0,01)$ no momento pós-colostro. Houve aumento no número de leucócitos totais $(\mathrm{P}<0,001)$ e nas contagens absolutas de neutrófilos segmentados $(\mathrm{P}<0,05)$ e de linfócitos $(\mathrm{P}<0,01)$ após a ingestão de colostro. As concentrações de PPT e de fibrinogênio também aumentaram no momento pós-colostro $(\mathrm{P}<0,001$ e $\mathrm{P}<0,01$, respectivamente). O eritroleucograma, as concentrações de PPT e de fibrinogênio variam consideravelmente antes e após a ingestão de colostro, sendo modificados em função da própria ingestão do colostro e/ou da adaptação dos processos físiológicos do animal à vida extrauterina. Portanto, recomenda-se que a interpretação de hemogramas realizados em cordeiros recém-nascidos seja feita com base em intervalos de referência específicos para o período neonatal. Palavras-chave: eritrograma; hemograma; leucograma; neonato; ovino.

\begin{abstract}
The aim of this study was to characterize the dynamics of some hematological parameters in healthy newborn lambs before and after colostrum intake. Blood samples of 28 newborn lambs were collected, determining the erythro-leukogram, the total plasma protein (TPP) and fibrinogen concentrations in pre and post-colostrum moments. The data were analyzed comparing the variability of the parameters between the two moments. The packed cell volume $(\mathrm{P}<0.001)$, the hemoglobin concentration $(\mathrm{P}<0.05)$ and the mean corpuscular volume $(\mathrm{MCV})(\mathrm{P}<0.05)$ decreased after colostrum intake, while the mean corpuscular hemoglobin concentration $(\mathrm{MCHC})$ increased $(\mathrm{P}<0.01)$ at the
\end{abstract}


post-colostrum moment. There was an increase in the total white blood cell count $(\mathrm{P}<0.001)$ and in the absolute counts of segmented neutrophils $(\mathrm{P}<0.05)$ and lymphocytes $(\mathrm{P}<0.01)$ after colostrum intake. The TPP and fibrinogen concentrations also increased at the post-colostrum moment $(\mathrm{P}<0.001$ and $\mathrm{P}<0.01$, respectively). The erythro-leukogram, the TPP and fibrinogen concentrations vary considerably before and after colostrum intake, being modified according to the own colostrum intake and/or the adaptation of the physiological processes of the animal to the extrauterine life. Therefore, it is recommended that the interpretation of complete blood cell counts performed in newborn lambs be made based on the specific reference intervals for the neonatal period.

Keywords: complete blood cell count; erythrogram; leukogram; neonate; sheep.

Recebido em: 20 de junho de 2013.

Aceito em: 08 de maio de 2018.

\section{Introdução}

Os exames hematológicos são fundamentais para investigação de problemas médicos em ruminantes e podem ser considerados um importante complemento do exame físico ${ }^{(1)}$. A adequada interpretação do hemograma, combinada ao histórico médico do animal, auxilia no diagnóstico diferencial de diversas enfermidades e frequentemente proporciona um prognóstico mais acurado e facilita a escolha para a melhor estratégia de tratamento ${ }^{(2)}$. Porém, para que isso seja possível, é necessário o conhecimento prévio sobre os valores de referência dos parâmetros sanguíneos de animais sadios, bem como sobre sua dinâmica e os fatores que atuam sobre a mesma ${ }^{(3,4)}$.

Em 1978, Fan e Schons ${ }^{(5)}$ estabeleceram valores para os parâmetros hematológicos de 100 ovinos adultos saudáveis criados a pasto no município de Santa Maria/RS. Desde então, apenas nos últimos 15 anos houve interesse dos pesquisadores na busca pelo estabelecimento de valores de referência em função da idade e fases do ciclo reprodutivo do rebanho ovino brasileiro ${ }^{(6-15)}$. Apesar disso, estudos específicos sobre a dinâmica dos parâmetros hematológicos na fase neonatal ainda são raros e muitas vezes os intervalos de referência utilizados na avaliação de cordeiros recém-nascidos ainda são baseados em valores determinados para animais adultos. Dessa forma, apesar da importância, existem grandes desafios para realização de diagnósticos e medidas terapêuticas eficazes para diversas enfermidades neonatais.

O período neonatal é considerado um dos períodos mais críticos na vida de um animal, pois representa a fase de transição entre o ambiente intrauterino e o extrauterino, no qual os recém-nascidos passam por intensas mudanças físiológico-metabólicas e são expostos a diversas condições infeciosas pela primeira $\mathrm{vez}^{(16,17)}$. Nesse período, os animais encontram-se mais susceptíveis às doenças perinatais e os índices de morbidade e mortalidade tornam-se mais elevados, resultando em graves perdas ao sistema de produção ${ }^{(18)}$.

Os pequenos ruminantes têm placentação do tipo sindesmocorial, o que impossibilita a adequada transferência de anticorpos da mãe para o feto. Assim, os recém-nascidos dessas espécies nascem hipo ou agamaglobulinêmicos, com baixa imunidade, e sua sobrevivência depende do consumo de colostro nas primeiras horas de vida $^{(19,20)}$. O colostro fornece o aporte de nutrientes e de defesa imunológica necessário aos recém-nascidos e interfere sobre muitas características metabólicas que são modificadas de acordo com a idade ${ }^{(21,22)}$. 
Gama et al. ${ }^{(8)}$, David et al. ${ }^{(1)}$ e Feitosa et al. ${ }^{(23)}$ avaliaram a dinâmica dos parâmetros do leucograma e/ou do eritrograma de cordeiros entre diferentes idades e raças, grupos etários e tipos de nascimento (nascidos a termo ou prematuros), respectivamente, durante as primeiras horas e/ou semanas de vida, mas não avaliaram especificamente a influência do colostro sobre o perfil sanguíneo. No entanto, acredita-se que o consumo do colostro, assim como outros fatores, também exerça influência sobre o desenvolvimento das respostas hematológicas neste período.

Nesse contexto, o objetivo deste estudo foi caracterizar a dinâmica das variáveis do eritroleucograma, das concentrações de proteína plasmática total (PPT) e de fibrinogênio em cordeiros recém-nascidos sadios, antes e após a ingestão de colostro, fornecendo subsídios que contribuam para interpretação de exames laboratoriais durante o período neonatal.

\section{Material e Métodos}

O protocolo experimental (016/2011 de 04 de agosto de 2011) foi aprovado pela Comissão de Ética no Uso de Animais do Setor de Ciências Agrárias, da Universidade Federal do Paraná, Brasil.

O estudo foi conduzido no Laboratório de Produção e Pesquisa em Ovinos e Caprinos (LAPOC), da

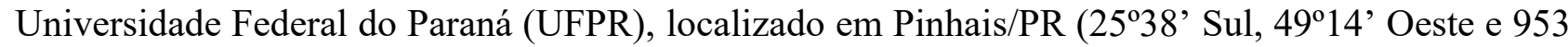
$\mathrm{m}$ de altitude). Foram coletadas amostras de sangue pré e pós-colostrais de 28 cordeiros sadios (13 mestiços $1 / 2$ Suffolk x $1 / 2$ White Dorper, nascidos entre setembro e outubro de 2010 - primavera; e 15 Suffolk PO, nascidos em agosto de 2011 - final do inverno), sendo 21 fêmeas e sete machos.

As amostragens sanguíneas pré-colostrais foram obtidas logo após o nascimento, antes da primeira mamada. As amostragens do momento pós-colostro foram realizadas às 72 horas de vida (após certificação da ingestão de colostro durante a primeira hora após o nascimento). Nesse período, os cordeiros permaneceram com suas respectivas mães e foi realizada a desinfecção umbilical (iodo a $10 \%$, uma vez ao dia).

Em ambos os momentos, foram coletadas amostras de $1 \mathrm{~mL}$ de sangue por venopunção jugular, utilizando-se seringas de $5 \mathrm{~mL}$ com agulhas hipodérmicas $0,8 \times 25 \mathrm{~mm}$. As amostras de sangue foram transferidas para tubos eppendorfes com $0,01 \mathrm{~mL}$ de anticoagulante EDTA a 10\%, homogeneizadas e resfriadas $\left(4^{\circ} \mathrm{C}\right)$ até o processamento das análises, que não excedeu o período máximo de 24 horas após a coleta. Todos os exames foram realizados no Laboratório de Patologia Clínica Veterinária da UFPR.

No eritrograma, determinou-se o número total de eritrócitos e a concentração de hemoglobina em analisador hematológico (BC-2800 Vet, Myndray ${ }^{\circledR}$ ). Os valores de hematócrito foram determinados pela técnica do micro-hematócrito ${ }^{(24)}$, utilizando-se tubos capilares e centrifugação a 11.000 RPM por 8 minutos. Posteriormente, foram calculados os índices hematimétricos, volume globular médio (VGM) e concentração de hemoglobina globular média (CHGM), conforme metodologia descrita por Wintrobe ${ }^{(25)}$.

A contagem do número de leucócitos totais foi determinada por leitura manual em câmara de Neubauer, mediante diluição na proporção de 1:20 entre sangue e ácido acético a 4\%, em duplicata. No processamento das amostras, foram confeccionados esfregaços sanguíneos que, após secagem, foram corados pelo método Panótico Rápido (Instant Prov, Newprov ${ }^{\circledR}$ ). Nas lâminas coradas foram diferenciados 100 leucócitos (em neutrófilos bastonetes e segmentados, linfócitos, monócitos, 
eosinófilos e basófilos).

Também foram determinadas as concentrações de PPT pelo método de refratometria e de fibrinogênio plasmático pelo método de precipitação térmica ${ }^{(26)}$.

Os dados foram submetidos ao teste de normalidade de Shapiro-Wilk $(\mathrm{P}=0,05)$. Os parâmetros que apresentaram resíduos com distribuição normal foram submetidos à análise de variância (ANOVA) e as médias comparadas pelo teste $T$ de Student $(\mathrm{P}=0,05)$. Os parâmetros que não atenderam à condição de normalidade dos resíduos foram submetidos ao teste não-paramétrico de Kruskal Wallis $(\mathrm{P}=0,05)$. A análise estatística foi realizada utilizando-se o programa $R$ Project for Statistical Computing, versão 2.10.1(27).

\section{Resultados e Discussão}

Não houve variação significativa $(\mathrm{P}>0,05)$ no número total de eritrócitos entre os momentos avaliados (Tabela 1). Gama et al. ${ }^{(8)}$ também não observaram variação no número de eritrócitos de cordeiros Morada Nova x Dorper entre 0-8 e 8-15 dias de idade, no entanto verificaram diminuição desse parâmetro em cordeiros Rabo Largo x Dorper e Santa Inês x Dorper no mesmo período. Entretanto, esses autores não estudaram especificamente a variação ocorrida entre o momento pré e pós-colostro.

Normalmente, o número de eritrócitos, a porcentagem de hematócrito e as concentrações de hemoglobina dos cordeiros são altas no momento imediato após o nascimento (com valores próximos ou até mais elevados que os encontrados para adultos da mesma raça), diminuem no decorrer das primeiras semanas de vida e novamente aumentam e se estabilizam a partir do primeiro mês de vida $^{(28)}$.

A diminuição pós-colostral na contagem de eritrócitos dos cordeiros deste estudo pode não ter sido observada no momento da avaliação devido a alguma oscilação na dinâmica do parâmetro, mas provavelmente ocorreu horas antes ou após as 72 horas de vida. Ullrey et al. ${ }^{(28)}$, ao avaliarem cordeiros Hampshire, Shropshire e Suffolk, verificaram redução na contagem de eritrócitos após a ingestão de colostro, porém os valores apresentaram considerável oscilação entre 10,33 e 8,79 $\mathrm{x} 10^{6} / \mu \mathrm{L}$ desde as primeiras seis horas até o oitavo dia de vida.

Tabela 1. Médias e erros-padrão $(\mathrm{M} \pm \mathrm{EP})$ do eritrograma de cordeiros recém-nascidos, antes e após 72 horas da ingestão de colostro

\begin{tabular}{lccc}
\hline Parâmetros eritrocitários & Pré-colostro & Pós-colostro & P \\
\hline${ }^{1}$ Eritrócitos $(\times 10 \% / \mu \mathrm{L})$ & $9,90 \pm 0,41$ & $8,77 \pm 0,33$ & $\mathrm{NS}$ \\
${ }^{1}$ Hematócrito $(\%)$ & $44,5 \pm 1,5$ & $36,3 \pm 1,3$ & $* * *$ \\
${ }^{1}$ Hemoglobina $(\mathrm{g} / \mathrm{L})$ & $131,6 \pm 6,1$ & $117,1 \pm 4,5$ & $*$ \\
${ }^{2} \mathrm{VGM}\left(\mu \mathrm{m}^{3}\right)$ & $45,3 \pm 1,0$ & $41,8 \pm 1,5$ & $*$ \\
${ }^{1} \mathrm{CHGM}(\%)$ & $29,5 \pm 0,7$ & $32,3 \pm 0,5$ & $*$ \\
\hline
\end{tabular}

VGM = volume globular médio; $C H G M=$ concentração de hemoglobina globular média.

${ }^{1}$ Médias comparadas pelo teste $\mathrm{t}$ de Student.

2 Média comparada pelo teste de Kruskal Wallis.

$*$, **, ***, indicam $\mathrm{P} \leq 0,05 ; \mathrm{P} \leq 0,01$ e $\mathrm{P} \leq 0,001$, respectivamente.

$\mathrm{NS}=$ ausência de diferença estatística significativa entre as médias $(\mathrm{P}>0,05)$. 
Houve diminuição significativa nos valores de hematócrito $(\mathrm{P}<0,001)$ e nas concentrações de hemoglobina $(\mathrm{P}<0,05)$ no momento pós-colostro (Tabela 1). Resultados semelhantes foram observados por Feitosa et al. ${ }^{(23)}$ tanto em cordeiros nascidos de partos normais como em cordeiros prematuros nascidos por meio de cesarianas, que observaram diminuição gradativa dos valores de hematócrito e de hemoglobina do momento após o nascimento até as primeiras 48 de vida.

A diminuição do hematócrito é uma consequência da ação de uma série de fatores que levam os animais ao desenvolvimento de um quadro de anemia fisiológica durante os primeiros dias de vida: a absorção de grande quantidade de colostro, principalmente de proteínas, que modificam o equilíbrio osmótico intravenoso e causam hemodiluição pela rápida expansão do volume plasmático total; o curto tempo de vida dos eritrócitos fetais, associado à menor taxa de renovação e produção de eritrócitos durante o período neonatal; e o menor estímulo para produção de eritropoietina, devido à transfusão de sangue via placenta, que aumenta a massa eritrocitária imediatamente após o nascimento, e ao rápido aumento do aporte de oxigênio disponível ao recém-nascido no ambiente extrauterino $^{(29)}$.

A diminuição dos valores de hemoglobina pode ser atribuída ao aumento da oferta tecidual de oxigênio após o nascimento, em decorrência da respiração pulmonar e do aumento dos níveis eritrocitários de 2,3 difosfoglicerato, que compete com o oxigênio pela ligação com a hemoglobina ${ }^{(30)}$. Além disso, a baixa transferência de ferro através da placenta somada à reduzida reserva de ferro no nascimento e ao baixo teor de ferro no colostro e no leite materno resultam numa menor quantidade de ferro disponível para a formação de hemoglobina durante o período neonatal, semelhante ao que ocorre em leitões ${ }^{(31)}$.

Por sua vez, o menor aporte de hemoglobina ocasiona diminuição no tamanho dos eritrócitos ${ }^{(32)}$. A própria formação de eritrócitos definitivos requer, na evolução de suas etapas de maturação, que o volume da célula naturalmente diminua, com a expulsão do núcleo, diminuição do tamanho de organelas, além de proporcional aumento de hemoglobina citoplasmática, o que resulta em uma estrutura pequena e bicôncava, com o máximo de área de superfície para as trocas gasosas ${ }^{(33)}$. Boyd e Bolon ${ }^{(34)}$ citaram que, em condições normais, os eritrócitos fetais podem ser até seis vezes maiores que os eritrócitos definitivos, o que permitiria diferenciá-los somente com base em seu tamanho.

Por essa razão, no momento pós-colostro constatou-se diminuição nos valores de $\operatorname{VGM}(\mathrm{P}<0,05)$ e aumento dos valores da CHGM $(\mathrm{P}<0,01)$ nos cordeiros (Tabela 1). De modo semelhante, Ullrey et al. ${ }^{(28)}$ observaram que, de fato, cordeiros frequentemente têm maiores valores de VGM e menores de CHGM ao nascimento, seguindo-se à combinação inversa deste comportamento com o avanço da idade.

O número de leucócitos totais apresentados pelos cordeiros aumentou $(\mathrm{P}<0,001)$ em média $82,4 \%$ entre os momentos pré e pós-colostro (Tabela 2). Ayres et al. ${ }^{(4)}$ observaram que a contagem leucocitária em cabritos com duas semanas de vida foi cerca de duas vezes maior do que a contagem encontrada antes do consumo de colostro. De forma geral, nos pequenos ruminantes o número de leucócitos circulantes logo após o nascimento representa o aporte celular formado no saco vitelínico (no estágio embrionário e fetal do desenvolvimento hematopoiético), perfazendo uma contagem de $20 \%$ dos níveis adultos, cujo aumento gradativo deve ocorrer ao longo das primeiras semanas de vida $^{(34)}$.

A elevação no número de leucócitos totais provém principalmente do aumento das linhagens neutrofílica e linfocitária, após a ingestão de colostro (Tabela 2). Isso ocorre provavelmente porque cordeiros recém-nascidos recebem uma quantidade significativa de células através das secreções 
mamárias, dentre as quais se destacam neutrófilos e linfócitos ${ }^{(35)}$.

Os linfócitos representam 20 a $25 \%$ das células que compõem o colostro ovino ${ }^{(36)}$. Assim, seu aumento $(\mathrm{P}<0,01)$ no momento pós-colostro pode estar relacionado ao recebimento direto de linfócitos $\mathrm{T}$, e em menor proporção de linfócitos $\mathrm{B}$, pela amamentação. Além disso, a consolidação dessa linhagem nos primeiros dias de vida deriva de uma elevada resposta linfocitária para mitógenos não específicos e para maior formação de anticorpos induzida após a amamentação colostral, como ocorre em bezerros ${ }^{(37)}$.

$\mathrm{O}$ aumento pós-colostral $(\mathrm{P}<0,05)$ no número absoluto de neutrófilos segmentados (Tabela 2), também está relacionado ao suprimento dessas células via colostro. Os neutrófilos e macrófagos predominam nas secreções mamárias de muitas espécies, embora, dentro da normalidade, a capacidade funcional neutrofílica é baixa e se vincula apenas à defesa da glândula mamária ${ }^{(35)}$. Porém, Loste et al. ${ }^{(38)}$ observaram que, após o cordeiro ingerir o colostro, a capacidade de opsonização e fagocitose pelos neutrófilos segmentados e células mononucleares aumentam significativamente ainda nas primeiras quatro horas após o nascimento. Em concordância, o estudo de Kampen et al. ${ }^{(39)}$ com bezerros confirma que os neutrófilos podem exercer respostas efetivas contra agentes infecciosos mesmo na primeira semana de vida.

Tabela 2. Médias e erros-padrão $(\mathrm{M} \pm \mathrm{EP})$ do leucograma de cordeiros recém-nascidos, antes e após 72 horas da ingestão de colostro

\begin{tabular}{|c|c|c|c|}
\hline Parâmetros leucocitários & Pré-colostro & Pós-colostro & $\mathbf{P}$ \\
\hline${ }^{2}$ Leucócitos totais $(/ \mu \mathrm{L})$ & $3.496 \pm 361$ & $6.378 \pm 652$ & $* * *$ \\
\hline \multicolumn{4}{|l|}{ Linfócitos } \\
\hline${ }^{1}$ Absoluta $(/ \mu \mathrm{L})$ & $1.853 \pm 278$ & $2.657 \pm 188$ & $* *$ \\
\hline${ }^{1}$ Relativa (\%) & $54,3 \pm 6,0$ & $46,2 \pm 3,7$ & NS \\
\hline \multicolumn{4}{|l|}{ Neutrófilos segmentados } \\
\hline${ }^{2}$ Absoluta $(/ \mu \mathrm{L})$ & $1.602 \pm 247$ & $3.603 \pm 633$ & $*$ \\
\hline${ }^{1}$ Relativa (\%) & $44,7 \pm 5,9$ & $52,2 \pm 3,7$ & NS \\
\hline \multicolumn{4}{|l|}{ Neutrófilos bastonetes } \\
\hline${ }^{2}$ Absoluta $(/ \mu \mathrm{L})$ & $4 \pm 4$ & $29 \pm 24$ & NS \\
\hline${ }^{2}$ Relativa (\%) & $0,1 \pm 0,1$ & $0,3 \pm 0,3$ & NS \\
\hline \multicolumn{4}{|l|}{ Monócitos } \\
\hline${ }^{2}$ Absoluta $(/ \mu \mathrm{L})$ & $37 \pm 16$ & $77 \pm 24$ & NS \\
\hline${ }^{2}$ Relativa (\%) & $1,0 \pm 0,4$ & $1,2 \pm 0,4$ & NS \\
\hline \multicolumn{4}{|l|}{ Eosinófilos } \\
\hline Absoluta $(/ \mu \mathrm{L})$ & $0 \pm 0$ & $18 \pm 13$ & - \\
\hline Relativa (\%) & $0,0 \pm 0,0$ & $0,2 \pm 0,2$ & - \\
\hline \multicolumn{4}{|l|}{ Basófilos } \\
\hline${ }^{2}$ Absoluta $(/ \mu \mathrm{L})$ & $0 \pm 0$ & $2 \pm 2$ & NS \\
\hline${ }^{2}$ Relativa (\%) & $0,0 \pm 0,0$ & $0,1 \pm 0,1$ & NS \\
\hline${ }^{2}$ Razão neutrófilo:linfócito & $1,09 \pm 0,25$ & $1,51 \pm 0,31$ & NS \\
\hline
\end{tabular}

${ }^{1}$ Médias comparadas pelo teste $t$ de Student.

2 Médias comparadas pelo teste de Kruskal Wallis.

$*$, ** ***, indicam $\mathrm{P} \leq 0,05 ; \mathrm{P} \leq 0,01$ e $\mathrm{P} \leq 0,001$, respectivamente.

$\mathrm{NS}=$ ausência de diferença estatística significativa entre as médias $(\mathrm{P}>0,05)$.

As elevações na contagem de neutrófilos bastonetes ocorrem preponderantemente em casos de inflamações severas. Nessa condição, a medula óssea, na tentativa de debelar a injúria, intensifica a 
produção de neutrófilos, ocasionando os desvios nucleares de neutrófilos à esquerda (DNNE) em que há liberação de células precursoras para a circulação ${ }^{(40)}$. Em ruminantes saudáveis, entretanto, tal como observado entre os cordeiros deste estudo (Tabela 2), não devem ocorrer diferenças significativas na contagem de neutrófilos bastonetes durante toda a fase neonatal, havendo interposição dessas células apenas em pequenas quantidades no perfil leucocitário ${ }^{(1)}$.

Quanto à razão neutrófilo:linfócito dos cordeiros, não foi observada diferença significativa $(\mathrm{P}>0,05)$ entre as amostragens. Contudo, ambas as médias foram superiores à média de 1:2 relatada em ovinos adultos $^{(1)}$. De forma similar, Ullrey et al. ${ }^{(41)}$ registraram uma razão neutrófilo:linfócito maior do que 1,0 em cordeiros após o nascimento, com menor proporção de neutrófilos e maior de linfócitos no momento anterior à ingestão de colostro, seguida pela elevação gradual do número de neutrófilos durante os primeiros meses de vida.

Segundo Jain ${ }^{(42)}$, o alto valor para a razão neutrófilo:linfócito durante a fase pós-natal imediata devese ao estresse atribuído aos cordeiros durante o momento do nascimento, visto que essa variação não é verificada em cordeiros nascidos por cesariana.

Em relação aos eosinófilos, basófilos e monócitos, também não houve diferenças significativas $(\mathrm{P}>0,05)$ entre os momentos avaliados, observando-se baixas concentrações dessas linhagens no sangue dos cordeiros (Tabela 2).

De fato, os eosinófilos e basófilos estão em baixas proporções no sangue de animais domésticos saudáveis $(10 \%$ e $0,5 \%$, respectivamente). A elevação dessas linhagens está associada, principalmente, aos casos de parasitemia, alergias e reações de hipersensibilidade ${ }^{(43,44)}$. Os monócitos nos ruminantes, por sua vez, apresentam alterações dignas de nota apenas em condições de inflamações severas, endotoxemias ou como parte do leucograma de estresse ${ }^{(40)}$. Dessa forma, em cordeiros sadios, o aumento relevante dessas linhagens não deve ser esperado.

Ressalta-se, no entanto, que o conjunto de dados obtidos para o número de eosinófilos nesta pesquisa não permitiu definir um valor de significância próprio perante os testes estatísticos definidos, não sendo possível certificar se houve ou não diferença estatística entre os momentos avaliados. Isso ocorreu, provavelmente, devido à repetição de valores nulos para este parâmetro em ambos os momentos de avaliação, existindo apenas três cordeiros com valores pontuados no pós-colostro (116, 132 e 206 eosinófilos/ $\mu \mathrm{L}$ ), o que resultou nas médias expostas na Tabela 2.

Apesar disso, há comprovações de que o número de eosinófilos deve ser geralmente baixo nesse período, atingindo picos de apenas $2,0 \%$ na contagem relativa de cordeiros com um mês de idade ${ }^{(41)}$.

Houve aumento $(\mathrm{P}<0,01)$ da concentração de PPT no momento pós-colostro (Tabela 3). Nas primeiras horas de vida, esta variação é diretamente relacionada ao aumento das concentrações de globulinas totais no sangue após a colostragem ${ }^{(22)}$. Os ruminantes não recebem proteínas e anticorpos em quantidades suficientes por via transplacentária; por isso, ao nascer, suas concentrações de proteínas totais e de globulinas são mínimas. Porém, conforme o recém-nascido absorve as imunoglobulinas maternas pelo consumo de colostro, estas concentrações se elevam rapidamente ${ }^{(17)}$. 
TABELA 3. Médias e erros-padrão $(\mathrm{M} \pm \mathrm{EP})$ das concentrações de proteína plasmática total e de fibrinogênio de cordeiros recém-nascidos, antes e após 72 horas da ingestão de colostro

\begin{tabular}{lccc}
\hline Parâmetros proteicos & Pré-colostro & Pós-colostro & P \\
\hline${ }^{1}$ PPT (g/L) & $45,8 \pm 0,7$ & $66,7 \pm 1,6$ & $* * *$ \\
${ }^{2}$ Fibrinogênio (mg/dL) & $67 \pm 28$ & $344 \pm 48$ & $* *$ \\
\hline
\end{tabular}

$\mathrm{PPT}=$ proteína plasmática total.

${ }^{1}$ Média comparada pelo teste $\mathrm{t}$ de Student.

2 Média comparada pelo teste de Kruskal Wallis.

$*$, **, ***, indicam $\mathrm{P} \leq 0,05 ; \mathrm{P} \leq 0,01$ e $\mathrm{P} \leq 0,001$, respectivamente.

A determinação da concentração de fibrinogênio é complementar ao leucograma dos ruminantes, sendo muitas vezes melhor indicadora de inflamações que as próprias alterações no perfil leucocitário ${ }^{(1)}$. Neste estudo, a concentração pós-colostral de fibrinogênio foi cerca de cinco vezes maior $(\mathrm{P}<0,01)$ do que aquela observada no momento pré-colostro (Tabela 3$)$. No entanto, esse aumento não deve ser associado a algum processo inflamatório, pois, assim como em bezerros, é normal que durante os primeiros dias de vida a concentração média de fibrinogênio aumente significativamente, ainda que representando apenas uma baixa proporção em termos de massa das proteínas totais, devido ao amadurecimento do fígado e da intensificação de sua capacidade para síntese desta e de outras proteínas hepáticas ${ }^{(45)}$.

\section{Conclusões}

O hematócrito, a concentração de hemoglobina, o VGM, a CHGM, o número de leucócitos totais, as contagens absolutas de neutrófilos segmentados e de linfócitos, e as concentrações de PPT e de fibrinogênio variam consideravelmente antes e após a ingestão de colostro, sendo modificados em função da própria ingestão do colostro e/ou da adaptação dos processos fisiológicos do animal à vida extrauterina. Dessa forma, é recomendável que a interpretação de hemogramas realizados em cordeiros recém-nascidos seja feita com base em intervalos de referência específicos para o período neonatal.

As dinâmicas do hematócrito, do número de leucócitos totais, das contagens absolutas de neutrófilos segmentados e de linfócitos, e das concentrações da PPT são influenciadas diretamente pelo consumo de colostro e, portanto, em conjunto, poderiam servir como medida indireta para a avaliação da ingestão de colostro por cordeiros neonatos sadios.

\section{Agradecimentos}

Alda Lúcia Gomes Monteiro é membro da Rede MARCARNE, pertencente ao CYTED (ref. 116RT0503). Os autores agradecem o apoio de todos os alunos e funcionários do LAPOC-UFPR e do Laboratório de Patologia Clínica Veterinária da UFPR.

\section{Referências}

1. Jones ML, Allison RW. Evaluation of the ruminant complete blood cell count. Veterinary Clinics Food 
Animal Practice [periódico na Internet]. 2007;23(3):377-402. Disponível em: https://doi.org/10.1016/j.cvfa.2007.07.002

2. Polizopoulou ZS. Haematological tests in sheep health management. Small Ruminant Research [periódico na Internet]. 2010;92(1-3):88-91. Disponível em: https://www.sciencedirect.com/science/article/pii/S0921448810001100

3. Birgel Júnior EH, D’Angelino JL, Benesi FJ, Birgel EH. Valores de referência do eritrograma de bovinos da raça Jersey criados no Estado de São Paulo. Arquivo Brasileiro de Medicina Veterinária e Zootecnia [periódico na Internet]. 2001;53(2):1-9. Disponível em: http://dx.doi.org/10.1590/S0102-09352001000200006

4. Ayres MCC, Dorea RD, Birgel Júnior EH, Viana RB, Lara MCCSH, Bittencourt TCBSC, Birgel EH. Dinâmica do leucograma de caprinos jovens, do nascimento até seis meses de idade: influência do fator racial. Ciência Animal Brasileira [periódico na Internet]. 2009;10(Supl. 1):261-266. Disponível em: http://revistas.ufg.br/vet/article/view/7761/5554

5. Fan LCR, Schons JAB. Valores hematológicos de ovinos adultos normais no município de Santa Maria. Revista do Centro de Ciências Rurais [periódico na Internet]. 1978;8(1):1-5. Disponível em: http://coral.ufsm.br/revistaccr/index.php/RCCCR/article/view/263/262

6. Ferreira AF, Rêgo EW, Melo LEH, Melo MT, Mendes EI, Galindo RCG, Menezes ÉSB. Eritrograma de ovinos (Ovis aries, LINNAEUS, 1758) da raça Santa Inês, clinicamente sadios, criados na Mesorregião Metropolitana de Recife. Influência dos fatores sexual e etário. Ciência Veterinária nos Trópicos [periódico na Internet]. 2003;6(2-3):89-95. Disponível em: http://revistas.bvs-vet.org.br/cvt/article/view/32650/36334

7. Brito MA, González FD, Ribeiro LA, Campos R, Lacerda L, Barbosa PR, Bergmann G. Composição do sangue e do leite em ovinos leiteiros do Sul do Brasil: variações na gestação e na lactação. Ciência Rural [periódico na Internet]. 2006;36(3):942-948. Disponível em: http://dx.doi.org/10.1590/S0103$\underline{84782006000300033}$

8. Gama SMS, Matos JR, Zacharias F, Chaves Filho RM, Guimarães JE, Bittencourt TCBSC, Ayres MCC. Dinâmica do eritrograma de cordeiros, resultantes do cruzamento entre animais de raças nativas criadas no Nordeste e a raça Dorper, desde o nascimento até os seis meses de idade. Revista Brasileira de Saúde e Produção Animal [periódico na Internet]. 2007;8(1):11-23. Disponível em: http://revistas.ufba.br/index.php/rbspa/article/view/692/435

9. Batista MCS, Castro RS, Rego EW, Carvalho FAA, Silva SMMS, Carvalho CCD, Riet-Correa F. Hemograma, proteinograma, ionograma e dosagens bioquímicas e enzimáticas de ovinos acometidos por conidiobolomicose no Nordeste do Brasil. Pesquisa Veterinária Brasileira [periódico na Internet]. 2009;29(1):17-24. Disponível em: http://dx.doi.org/10.1590/S0100-736X2009000100002

10. Santana AM, Silva DG, Bernardes PA, Pizauro LJL, Maluta RP, Aquino GV, Garcia KO, Ávila FA, Fagliari JJ. Hemograma e perfil bioquímico sérico de ovinos em idade de abate. Ciência Animal Brasileira [periódico na Internet]. 2009;10(Supl. 1):286-289. Disponível em: https://www.revistas.ufg.br/vet/article/view/7766

11. David CMG, Luquetti BC, Costa RLD, Bonello FL. Padrão hematológico de cordeiros da raça Santa Inês criados sob manejo semi-extensivo na região Oeste do Estado de São Paulo. Boletim de Indústria Animal [periódico na Internet]. 2012;69(1):79-84. Disponível em: http://revistas.bvsvet.org.br/bia/article/view/7183/7408

12. Bezerra LR, Torreão JNC, Marques CAT, Machado LP, Araújo MJ, Veiga AMS. Influência da suplementação concentrada e da categoria animal no hemograma de ovinos da raça Morada Nova. Arquivo Brasileiro de Medicina Veterinária e Zootecnia [periódico na Internet]. 2013;65(6):1738-1744. Disponível em: http://dx.doi.org/10.1590/S0102-09352013000600022

13. Madureira KM, Gomes V, Barcelos B, Zani BH, Shecaira CL, Baccili CC, et al. Parâmetros hematológicos e bioquímicos de ovinos da raça Dorper. Semina: Ciências Agrárias [periódico na Internet]. 2013;34(2):811816. Disponível em: http://dx.doi.org/10.5433/1679-0359.2013v34n2p811 
14. Lima MB, Monteiro MVB, Jorge EM, Campello CC, Rodrigues LFS, Viana RB et al. Intervalos de referência sanguíneos e a influência da idade e sexo sobre parâmetros hematológicos e bioquímicos de ovinos da raça Santa Inês criados na Amazônia Oriental. Acta Amazonica [periódico na Internet]. 2015;45(3):317322. Disponível em: http://dx.doi.org/10.1590/1809-4392201402115

15. Meneghini RCM, Benesi FJ, Henriques LCS, Rizzo H, Meira Junior EBS, Gregory L. Hemogram of healthy sheep (Ovis aries) of the Santa Ines breed raised in the region of Piedade, São Paulo State: influence of age and sex. Braz. J. Vet. Res. Anim. Sci. [periódico na Internet]. 2016;53(4):1-7. Disponível em: http://dx.doi.org/10.11606/issn.1678-4456.bjvras.2016.79665

16. Piccione G, Bertolucci C, Giannetto C, Giudice E. Clotting profiles in newborn Maltese kids during the first week of life. Journal of Veterinary Diagnostic Investigation [periódico na Internet]. 2008;20:114-118. Disponível em: http://dx.doi.org/10.1177/104063870802000126

17. Silva DFM, Costa JN, Araújo AL, Costa Neto AO, Almeida MÂO, Carvalho VS. Proteinograma sérico de cordeiros mestiços (Santa Inês x Dorper) do nascimento até o desmame: efeito do desenvolvimento etário e do monitoramento da ingestão de colostro. Ciência Animal Brasileira [periódico na Internet]. 2010;11(4):794805. Disponível em: http://dx.doi.org/10.5216/cab.v11i4.4848

18. Dwyer CM. The welfare of the neonatal lamb. Small Ruminant Research [periódico na Internet]. 2008;76(1):31-41. Disponível em: https://www.sciencedirect.com/science/article/pii/S0921448807002805

19. Britti D, Massimini G, Peli A, Luciani A, Boari A. Evaluation of serum enzyme activities as predictors of passive transfer status in lamb. Journal of American Veterinary Medical Association [periódico na Internet]. 2005;226(6):951-955. Disponível em: https://www.ncbi.nlm.nih.gov/pubmed/15786999

20. Silva SL, Fagliari JJ, Baroza PFJ, Cesco FTRS, Jorge RLN. Avaliação da imunidade passiva em caprinos recém-nascidos alimentados com colostro de cabras ou colostro de vacas. Ars Veterinaria [periódico na Internet]. 2007;23(2):81-88. Disponível em: http://arsveterinaria.org.br/index.php/ars/article/view/134/116

21. Hernández-Castellano LE, Almeida AM, Ventosa M, Coelho AV, Castro N, Argüello A. The effect of colostrum intake on blood plasma proteome profile in newborn lambs: low abundance proteins. BMC Veterinary Research [periódico na Internet]. 2014;10(85):1-9. Disponível em: https://doi.org/10.1186/1746$\underline{6148-10-85}$

22. Souza DF, Monteiro ALG, Dittrich RL, Schmidt EMS, Fernandes SR, Beltrame OC. Dinâmica pré e póscolostral de parâmetros bioquímicos em cordeiros. Ciência Animal Brasileira [periódico na Internet]. 2014;15(3):313-321. Disponível em: http://dx.doi.org/10.1590/1809-6891v15i324807

23. Feitosa FLF, Alcindo JF, Narciso LG, Bovino F, de Souza NC, Mendes LCN, Peiró JR, Perri SHV, Avila LG. Parâmetros hematológicos e perfil bioquímico renal de cordeiros nascidos a termo e prematuros. Arquivo Brasileiro de Medicina Veterinária e Zootecnia [periódico na Internet]. 2017;69(3):627-636. Disponível em: http://dx.doi.org/10.1590/1678-4162-9098

24. Farrand LL. The microhematocrit: technique and applications. The Nurse Practitioner [periódico na Internet]. 1976;1(5):19-20. Disponível em: https://www.ncbi.nlm.nih.gov/pubmed/1046565

25. Wintrobe MM. The size and hemoglobin content of erythrocyte. Methods of determination and clinical application - 1932. Journal of Laboratory Clinical Medicine [periódico na Internet]. 1990;115(3):374-387. Disponível em: https://www.ncbi.nlm.nih.gov/pubmed/2179436

26. Kaneko JJ, Smith $\mathrm{H}$. The estimation of plasma fibrinogen and its clinical significance in the dog. The California Veterinarian. 1967;21(4):21-24.

27. R Development Core Team. The R Project for Statistical Computing [Free Software Programming Language]. Version 2.10.1. Auckland (NZ): R Project; 2009. Disponível em: http://www.r-project.org

28. Ullrey DE, Miller ER, Long CH, Vincent BH. Sheep hematology from birth to maturity. I Erythrocyte population, size and hemoglobin concentration. Journal of Animal Science [periódico na Internet]. 1965a;24(1):135-140. Disponível em: http://dx.doi.org/10.2527/jas1965.241135x 
29. Harvey JW. The erythrocyte: physiology, metabolism, and biochemical disorders. In: Kaneko JJ, Harvey JW, Bruss ML (Eds.). Clinical Biochemistry of Domestic Animals. 6a. ed. San Diego: Academic Press; 2008. p. $173-240$.

30. Martins FF. Anemia no recém-nascido pretermo. In: Moreira MEL, Lopes JMA, Caralho M, orgs. O recémnascido de alto risco: teoria e prática do cuidar. Rio de Janeiro: Editora FIOCRUZ; 2004. p. 347-376.

31. Pissinin D. Ferro para leitões: revisão de literatura. Nutritime Revista Eletrônica [periódico na Internet]. 2016;13(6):4874-4882. Disponível em: http://docplayer.com.br/41890926-Ferro-para-leitoes-revisao-deliteratura.html

32. Mohri M, Sharifi K, Eidi S. Hematology and serum biochemistry of Holstein dairy calves: age related changes and comparison with blood composition in adults. Research in Veterinary Science [periódico na Internet]. 2007;83:30-39. Disponível em: http://dx.doi.org/10.1016/j.rvsc.2006.10.017

33. Junqueira LC, Carneiro J. Histologia Básica. 10ª ed. Rio de Janeiro: Guanabara Koogan; 2004. 488 p.

34. Boyd KL, Bolon B. Embryonic and fetal hematopoiesis. In: Weiss DJ, Wardrop KJ (Eds.). Schalm's Veterinary Hematology. $6^{\text {a }}$. ed. Iowa: Blackwell Publishing Ltd.; 2010. p. 3-7.

35. Le Jan C. Cellular components of mammary secretions and neonatal immunity: a review. Veterinary Research, BioMed Central [periódico na Internet]. 1996;27(4-5):403-417. Disponível em: https://hal.archivesouvertes.fr/hal-00902432

36. Ouzrout R, Guiguen F, Lerondelle C. Évolution des sous-populations lymphocytaires dans le lait de brebis au moment de l'excrétion du virus Maedi. Annales de Recherches Vétérinaires, INRA Editions [periódico na Internet]. 1991;22(4):379-386. Disponível em: https://hal.archives-ouvertes.fr/hal-00902042

37. Riedel-Caspari G. The influence of colostral leukocytes on the course of an experimental Escherichia coli infection and serum antibodies in neonatal calves. Veterinary Immunology and Immunopathology [periódico na Internet]. 1993;35(3-4):275-288. Disponível em: https://doi.org/10.1016/0165-2427(93)90039-7

38. Loste A, Ramos JJ, Fernández A, Ferre LM, Lacasta D, Verde MT, Marca MC, Ortín A. Effect of colostrum treated by heat on immunological parameters in newborn lambs. Livestock Science [periódico na Internet]. 2008;117(2-3):176-183. Disponível

https://www.sciencedirect.com/science/article/pii/S1871141307005665

39. Kampen AH, Olsen I, Tollersrud T, Storset AK, Lund A. Lymphocyte subpopulations and neutrophil function in calves during the first 6 months of life. Veterinary Immunology and Immunopathology [periódico na Internet]. 2006;113(1-2):53-63. Disponível em: https://doi.org/10.1016/j.vetimm.2006.04.001

40. Tornquist SJ, Rigas J. Interpretation of ruminant leukocyte responses. In: Weiss DJ, Wardrop KJ (Eds.). Schalm's Veterinary Hematology. 6a. ed. Iowa: Blackwell Publishing Ltd.; 2010. p. 307-313.

41. Ullrey DE, Miller ER, Long CH, Vincent BH. Sheep hematology from birth to maturity. II Leucocyte concentration and differential distribution. Journal of Animal Science [periódico na Internet].1965b;24(1):141144. Disponível em: http://dx.doi.org/10.2527/jas1965.241141x

42. Jain NC. Essentials of Veterinary Hematology. Philadelphia: Lea \& Febiger; 1993. 417 p.

43. Young KM, Meadows RL. Eosinophils and their disorders. In: Weiss DJ, Wardrop KJ (Eds.). Schalm's Veterinary Hematology. 6 ${ }^{\text {a }}$ ed. Iowa: Blackwell Publishing Ltd.; 2010. p. 281-289.

44. Pohlman LM. Basophils, mast cells, and their disorders. In: Weiss DJ, Wardrop KJ (Eds.). Schalm's Veterinary Hematology. 6 ${ }^{\text {a }}$ ed. Iowa: Blackwell Publishing Ltd.; 2010. p. 290-297.

45. Gentry PA, Ross ML, Hayatgheybi H. Competency of blood coagulation in the newborn calf. Research in Veterinary Science [periódico na Internet]. 1994;57(3):336-342. Disponível em: https://www.ncbi.nlm.nih.gov/pubmed/7871254 